\section{AS NARRATIVAS DA CIDADE NO APLICATIVO PORTO ALEGRE GUIDE}

\author{
Luis Fernando Herbert Massoni* \\ Marina Leitão Damin** \\ Valdir Morigi*** \\ Vera Dodebei****
}

RESUMO O artigo analisa as informações disponíveis sobre a cidade em um aplicativo de celular e a sua relação com a memória social. Engloba os fluxos informacionais que estruturam o aplicativo e atuam na virtualização da cidade. Ao percorrer a cidade por meio de sua representação virtual, deixamos rastros informacionais de nossa passagem, o que contribui para a construção de narrativas sobre ela. Utiliza a narratologia como método para analisar as informações disponíveis no aplicativo Porto Alegre Guide, caracterizando-o como uma fonte de informação sobre a cidade e sua memória. Enfoca na análise das informações que tratam dos enredos, dos episódios, dos personagens, dos cenários e das sequências cronológicas que compõem as histórias da cidade narradas pelo aplicativo. Conclui que todos esses elementos, embora distintos, convergem para uma mesma narrativa: Porto Alegre é uma cidade que agrega às tradições do passado, o vanguardismo do presente, ao mesmo tempo em que se mantém aberta às transformações do futuro.

Palavras-chave: Porto Alegre Guide. Narrativa. Memória Social. Aplicativo de Celular.
* Mestrando em Comunicação e Informação pela Universidade Federal do Rio Grande do Sul, Brasil.

E-mail: luisfernandomassoni@gmail.com.

** Mestre em Memória Social pela Universidade Federal do Estado do Rio de Janeiro, Brasil. Doutoranda em Memória Social pela Universidade Federal do Estado do Rio de Janeiro, Brasil.

E-mail: mldamin@gmail.com.

*** Doutor em Sociologia pela Universidade de Sao Paulo, Brasil. Professor Titular do Programa de Pós-graduação em Comunicação e Informação da Universidade Federal do Rio Grande do Sul, Brasil.

E-mail: valdir.morigi@gmail.com.

**** Doutora em Comunicaçao e Cultura pela Universidade Federal do Rio de janeiro, Brasil. Professora Titular do Programa de Pós-Graduação em Memória Social da Universidade Federal do estado do Rio de Janeiro, Brasil.

E-mail: dodebei@gmail.com.

\section{INTRODUÇÃO}

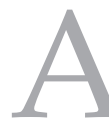

o transitarmos pela cidade, seja como moradores ou como turistas, desenvolvemos uma experiência com o lugar que orienta nossas concepções e também nossas ações sobre ele. Apreendemos a cidade em um processo marcado por nossos afetos e também pela atribuição de valores aos elementos que formam a paisagem urbana. Nesse processo, a cidade é enquadrada e nossas representações sobre ela auxiliam na construção da memória, tanto individual como social.

As informações que cotidianamente circulam na sociedade são fontes de novos significados para a cidade, ao lado da rememoração e do reconhecimento por parte dos habitantes, reforçando determinadas concepções sobre a cultura, a cidade e, consequentemente, sobre a memória social. Elas também se configuram como representações, pois são construídas e divulgadas sempre influenciadas por intencionalidades, apresentando-se como versões dos fatos. Presentes nos atos de fala dos mais diversos sujeitos sociais, essas informações compõem narrativas sobre a cidade e sua memória.

Tais narrativas vêm passando por transformações na forma como chegam até nós, pois nosso dia a dia é cada vez mais influenciado pelas Tecnologias de Informação e Comunicação (TICs), que alteram nosso acesso à informação e também nos tornam produtores dela. Com uma quantidade crescente de usuários, uma das 
principais fontes de informação que temos à nossa disposição atualmente são os aplicativos de celulares, facilmente acessíveis a qualquer pessoa que tenha em mãos um aparelho celular conectado à internet. Dentre as informações que acessamos por meio destes dispositivos estão as narrativas sobre nossa cidade e sua memória.

Tendo em vista esses aspectos, relatamos parte de nossa pesquisa a partir do seguinte questionamento: De que modo as informações divulgadas no aplicativo Porto Alegre Guide atuam na construção de uma narrativa sobre a cidade e suas memórias? Para nos orientarmos na análise das informações contidas no aplicativo, usamos como método a narratologia, entendendo que os conteúdos que circulam em tal dispositivo fazem parte de uma narrativa sobre a cidade.

\section{INFORMAÇÃO, MEMÓRIA E NARRATIVAS SOBRE A CIDADE}

A memória social é formada, dentre outros elementos, pelos mais variados discursos aos quais temos acesso, dentro dos grupos que interagimos. Para Halbwachs (2006), nossas lembranças estão atreladas às nossas experiências e fazem parte dos grupos de que fazemos ou fizemos parte e que ainda mantemos alguma relação. Podemos pensar a memória social como um organismo vivo, formado por diferentes grupos e dinâmicas sociais, que tem a cidade como um dos pontos de contato e rememoração.

Formada pelo entrecruzamento da experiência individual e a experiência coletiva, a memória social é fruto do que cada grupo produz e é guardada e transmitida por meio da interação entre seus membros (JEDLOWSKI, 2001). O destaque aqui recai sobre esse caráter construtivo da memória, revista e reinventada de acordo com nossas práticas de contato uns com os outros e com os lugares. Para Sá (2007), a memória social é complexa e multifacetada, não sendo uma reprodução de experiências passadas, mas uma construção em função da realidade, com recursos oriundos da sociedade e da cultura.

De acordo com Gondar (2016, p. 19), a memória "[...] é, simultaneamente, acúmulo e perda, arquivo e restos, lembrança e esquecimento" e "[...] sua única fixidez é a reconstrução permanente". Assim, não é à toa que o homem age sobre as construções da cidade em uma prática de criar, recriar, construir e restaurar, pois podemos sugerir que elas são uma materialidade que tem laços com a memória. As lembranças e esquecimentos, as ruínas e locais de uma cidade podem estabelecer um diálogo próximo, bem como um silêncio distanciado, com seus habitantes. Para Assmann (2011, p. 360),

\begin{abstract}
Assim como os objetos utilitários que, ao se tornarem peças de museu, perdem as funções originais e seu nexo com a vida prática, também as formas de vida, atitudes, ações e experiências estão sujeitas a uma metamorfose parecida, quando saem do contexto de uma atualidade viva e se tornam recordações.
\end{abstract}

A cidade e seus habitantes se metamorfoseiam e, o que antes era algo do cotidiano, acaba se tornando recordação. Isso porque os cidadãos, em suas práticas socioculturais, interagem de diversas formas com o ambiente urbano, moldando-o aos seus costumes e valores, atribuindo-lhe significados e construindo diferentes representações sobre ele. Nesse processo, marcado por tensões entre o passado e o presente, os espaços da cidade são apropriados pelos sujeitos, compondo sua memória social.

A memória é alimentada pelas informações às quais acessamos em nossas práticas comunicacionais cotidianas. A informação é entendida como uma construção, um processo de assimilação e formação de conhecimentos, aberta às dinâmicas sociais. A concepção de informação adotada aqui segue os parâmetros do paradigma social da informação, conforme caracterização de Capurro (2003). Essa perspectiva enfoca a constituição social dos processos informacionais, re-inserindo o sujeito em seus contextos concretos de vida e atuação. Amparamos essa escolha no fato de que a memória não é algo dado, mas em constante transformação, influenciada pelo seu contexto, que não pode ser ignorado. A comunicação e a sociabilidade são fundamentais na construção de nossas memórias, sendo o paradigma social da informação o que lhes dá um lugar de destaque.

A informação, sua produção, transferência e aquisição são fenômenos de ordem social e simbólica, não sendo algo pronto, mas construído a partir do contexto social e da atribuição de sentidos e símbolos dos indivíduos que a acessam (MARTELETO, 1995). Ela não é uma cópia 
fidedigna dos fatos reais, pois pode salientar certos aspectos do real em detrimento de outros. Conforme Latour (2004), quem recebe a informação pode interpretá-la de modo diferente do ocorrido. Assim, a informação é fruto de uma construção sociocultural, aberta às interpretações e aos enquadramentos dados pelos sujeitos que a acessam e a produzem.

A informação corrobora na apropriação subjetiva que fazemos do ambiente urbano. Segundo Boni e Hoffmann (2011), é a experiência que forma a realidade, ao passo que a percepção é um processo mental de interação entre o homem e seu ambiente. Desse modo, há um processo cognitivo em que os sentidos apreendem os estímulos, que são recebidos pelo cérebro. Os autores destacam as informações que são processadas de modo cíclico em uma retroalimentação de experiências, o que permite obter novas informações que podem influenciar vivências futuras.

A construção identitária é influenciada pela percepção da cidade e dos lugares de vivência, pois nos associamos com algumas partes da cidade e essas imagens se baseiam em lembranças e significados, o que nos torna mais do que apenas observadores, fazendo-nos "parte" do lugar (BONI; HOFFMANN, 2011). O contato com a cidade é cercado de atribuição de sentidos e valores diferenciados aos seus elementos, pois nossas experiências com ela moldam nossa relação com o lugar.

A concepção adotada da cidade difere da sua realidade concreta, dependendo das informações que acessamos que, ao circularem em diversos suportes, auxiliam-nos na produção das memórias da cidade. Enquanto cidadãos, nós mesmos somos produtores dessas informações, presentes nas histórias que narramos sobre a cidade. Essas histórias destacam alguns elementos em detrimento de outros, evidenciando o caráter subjetivo e parcial das informações produzidas no ato narrativo. Conforme Motta (2013), as narrativas tecem nossas vidas, nos entrelaçando, envolvendo, representando e constituindo, o que cria as representações de nós mesmos e das nossas identidades individuais e coletivas. Nesse sentido, estudar narrativas é identificar também resquícios de memórias individuais em cruzamento com a memória social. Para Barbosa (2003), a narrativa transforma os eventos em episódios e os atores sociais em personagens, enriquecendo substancialmente a identidade, formada na dinâmica entre a experiência e a narrativa. Segundo o autor, ela se realiza através da experiência, sendo característico dessa última, bem como do ato narrativo, a crença na memória do passado, o que permite reconstituir a experiência. Podemos complementar esse pensamento com Ítalo Calvino que, em As Cidades Invisíveis (1990, p. 7), dirá que a cidade é feita "[...] das relações entre as medidas de seu espaço e os acontecimentos do passado [...]" e que ela é como uma esponja que absorve as ondas de recordações e se dilata.

$\mathrm{O}$ estudo de narrativas revela percepções de mundo que estão permeadas de visões sobre a cidade, presentes na memória individual que se interliga com a memória do grupo social. Há um aspecto que não podemos ignorar ao analisarmos uma narrativa: a aproximação entre narração e ficção. Isso porque, conforme Leite (1997), o narrador narra aquilo que viu, viveu e testemunhou, mas também o que imaginou, sonhou e o que desejou. Ao narrar, o sujeito articula o possível com o desejado, revelando rupturas e continuidades e descortinando representações sobre si mesmo e sobre o mundo que o cerca.

As narrativas, conforme Motta (2013), são manifestadas através de suportes como testemunhos, cartas e relatos, mas contemporaneamente também vêm sendo contadas nos blogs e em redes sociais, o que transforma as narrativas fechadas em narrativas abertas, em desenvolvimento, parecendo não ambicionar o fim da história. $\mathrm{O}$ autor adverte que as narrativas constituem um "mar de relatos" em que deságuam diversas histórias, sendo que esse mar cada vez se torna mais polissêmico e polifônico, devido aos fluxos e refluxos do maremoto discursivo contemporâneo.

Incluem-se nesses discursos as fotos e os textos que circulam nos meios digitais e que são chamados por Van Dijck (2007) de mediated memory objects e, segundo a autora, eles são interessantes para as pessoas porque servem como um gatilho para as memórias pessoais. Partimos, então, do pressuposto de que as informações sobre a cidade às quais temos acesso, incluindo os mediated memory objects, narram uma história, compondo uma narrativa marcada por fragmentos de memórias e de histórias sobre a cidade. 


\section{NARRATOLOGIA COMO MÉTODO PARA O ESTUDO DA CIDADE}

O aplicativo Porto Alegre Guide apresenta uma narrativa sobre a cidade por meio de textos, ícones, fotos e do próprio mapa da cidade, formando uma espécie de cartografia memorial, em um suporte dinâmico e intuitivo. $\mathrm{O}$ aplicativo faz um intercâmbio entre o passado e o presente, aproximando-os por meio do artefato tecnológi$\mathrm{co}$, tendo como intermediário a figura do usuário - neste caso, o turista - que interage de forma temporal, virtual e espacial com a cidade.

Nosso interesse tem sido estudar as informações divulgadas no aplicativo Porto Alegre Guide, de modo a evidenciar como ele constrói uma narrativa sobre a cidade, desvendando as representações sobre seus lugares, os enquadramentos da cultura local e as características do cidadão porto alegrense. Tais informações se aproximam de uma história relatada através do aplicativo, algo que acontece e é contado por alguém. Metodologicamente, o primeiro passo tomado foi observar a forma como o aplicativo estrutura hierarquicamente e sequencialmente as informações, identificando o seu fluxo informacional. Isso permite entender as categorias criadas para organizar as informações presentes na narrativa do aplicativo.

Escolhemos a narratologia como método de análise das informações, pois ela nos permite caracterizar satisfatoriamente as representações, tomando como pressuposto de que tais informações não são necessariamente a verdade, mas fragmentos e uma versão dos fatos. Com base na narratologia, formulamos categorias que orientam a análise das informações. Partindo das considerações apontadas por autores como Barbosa (2003), Motta (2013) e Maronna e Vilela (2007), propomos analisar os seguintes elementos presentes nas narrativas:

a) Enredo: os temas narrados referentes às tradições, questões linguísticas, etc.;

b) Episódios: os acontecimentos narrados e que dinamizam a cidade;

c) Cenários: as características e peculiaridades dos espaços da cidade;

d) Personagens: a caracterização do cidadão porto alegrense;

e) Sequências cronológicas: referências ao passado, ao presente e ao futuro da cidade.
A observação desses elementos permitiu uma análise transversal das informações, levando em consideração os diversos aspectos que caracterizam a cidade, seus espaços, seus acontecimentos, seus cidadãos e sua memória. A distribuição dos lugares narrados pelos espaços da cidade ocorre de forma bem específica, compondo uma cartografia do lugar. Para tanto, construímos um mapa apontando os pontos turísticos indicados pelo aplicativo no centro da cidade, de modo a evidenciar a sua distribuição e suas centralidades.

\section{NARRATIVAS SOBRE A CIDADE NO APLICATIVO PORTO ALEGRE GUIDE}

Antes de procedermos à análise do aplicativo, apresentaremos nosso objeto de estudo e a forma como as informações estão dispostas nele. Porto Alegre Guide é um aplicativo de celular gratuito, lançado em 2014, compatível com os sistemas operacionais IOS e Android. Disponível em português, inglês e espanhol, possui como apelo comercial o discurso de ser feito por moradores e pensado para viajantes independentes.

O aplicativo tem em sua tela inicial dois botões: Compreenda e Experimente, apresentando a cidade de Porto Alegre por meio dessas duas navegações principais, que se interligam. Ao clicar em Compreenda, o aplicativo abre uma tela denominada Compreenda Porto Alegre. Nela, encontram-se cinco submenus: Porto Alegre $\mathcal{E}$ Jeito Gaúcho, Curiosidades, Conheça o Resto do Estado, Informações Úteis e Doses de Gauchês.

Já em Experimente, uma nova tela exibe um mapa da cidade, apresentando visualmente em ícones as oito categorias disponíveis: Ponto Turístico, Café/Outros, Festa, Para Comprar, Bar, Restaurante, Hostel e Atividade. Neste mapa, é possível marcar e desmarcar estas categorias, de acordo com o interesse do usuário. Além disso, o aplicativo oferece como possibilidade a criação de uma rota, partindo do local atual do GPS até o local escolhido. Também é possível navegar pelo aplicativo via menu, localizado no canto superior esquerdo da tela.

Ao navegar pelo Porto Alegre Guide, a narrativa se constrói fazendo emergir as 
categorias definidas como chave para a análise. Assim, foi possível perceber as representações que circulam sobre a cidade através das informações que compõe a narrativado aplicativo. A partir daí, identificamos o seu fluxo informacional, evidenciando de que modo as informações são apresentadas aos usuários que acessam o Porto Alegre Guide. Isso inclui não apenas a ordem das informações, mas também a sua arquitetura e as categorias estruturadas hierarquicamente, conforme ilustramos na Figura 1.

Figura 1 - Fluxo de Informações no Aplicativo Porto Alegre Guide
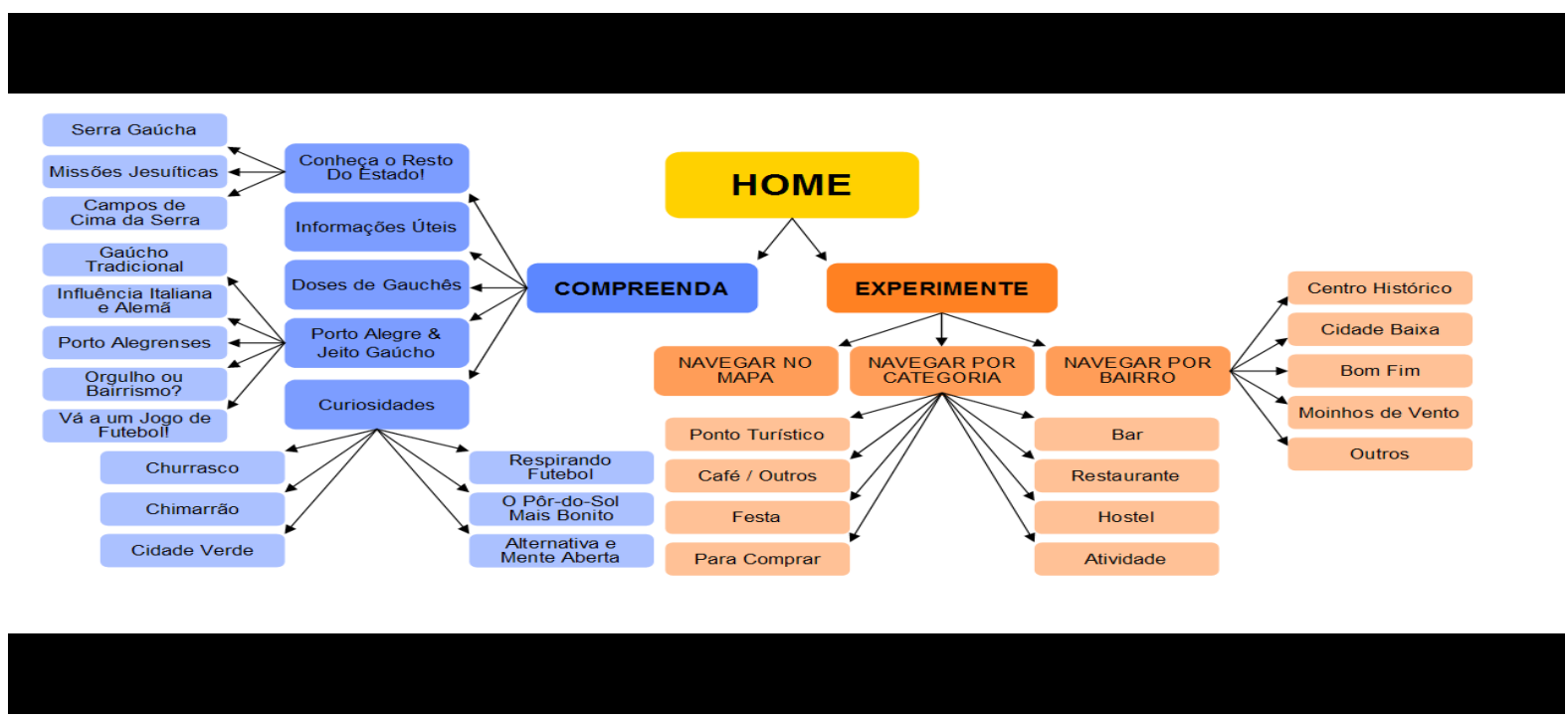

Fonte: os autores (2016)

A trajetória virtualmente traçada no aplicativo encontra em diversos momentos a materialidade dos bens patrimonializados para recontar a cidade de Porto Alegre. De acordo com Dodebei (2015, p. 22), “[...] memória e patrimônio constituídos no ambiente virtual são sempre mediados por objetos informacionais". Por meio deles, portanto, as representações da cidade se tornam possíveis, viabilizando a inserção de novos locais de forma dinâmica e colaborativa. Entretanto, é importante ressaltar que existe uma narrativa validada pelos proprietários do aplicativo. Por mais que exista uma construção colaborativa, há uma espécie de curadoria de conteúdo, responsável pela ativação ou pelo descarte dessas informações. Além disso, caso o conteúdo sugerido seja aprovado, ainda sofrerá uma interferência de forma, para que sua linguagem seja adaptada à proposta do aplicativo e associada a uma imagem ilustrativa.

De qualquer modo, acreditamos que esta ação não invalide o objetivo do aplicativo, por considerarmos que esta alteração seja uma espécie de tradução do conteúdo, mantendo seu cerne e tornando a narrativa mais fluida. E é nessa associação dos textos com as imagens e o mapa da cidade que a narrativa se constitui para dar voz às memórias da cidade e de seus habitantes. $\mathrm{O}$ ato de navegar pelo aplicativo já suscita o contato com essa memória, de certa forma espacial e temporal, fazendo com que o turista vá além do contemplativo, indo em direção ao interativo.

Assim, o aplicativo funciona não apenas como um guia turístico, mas se constitui uma fonte de informação responsável pela construção das memórias de Porto Alegre. É possível constatar essa dupla função a partir das diversas categorias utilizadas pelo aplicativo, como é o caso da categoria Compreenda. Neste espaço, pode-se perceber que existe uma narrativa que informa os usuários sobre os traços culturais e linguísticos da cidade e do estado, reforçando representações já conhecidas a respeito da 
história e uma memória enquadrada sobre o que é ser gaúcho.

Um exemplo disso é o conteúdo expresso no submenu Porto Alegre \& Jeito Gaúcho. Nele, é possível encontrar informações sobre a "influência alemã e italiana" no estado, a caracterização do "gaúcho tradicional", bem como uma discussão sobre o "orgulho" da identidade gaúcha, questionando se trata de orgulho ou bairrismo.

\section{I Personagens asnarrativassobre portoalegrenses}

Ao analisar as Personagens, elemento da narrativa anteriormente referido, observa-se atributos que caracterizam a cidade e o "Jeito Gaúcho". O aplicativo inicia a narrativa sobre os cidadãos apresentando a figura do gaúcho, que é a pessoa em que as representações estão associadas às atividades do campo e que reside no sul da América Latina, sendo designados com este nome no Brasil os que nascem no Rio Grande do Sul. Nas palavras do próprio aplicativo, esses indivíduos são assim descritos:

\begin{abstract}
Os gaúchos eram homens que optavam por uma vida de liberdade e se mudavam com frequência, influenciando muita gente na Argentina, no Uruguai e no Rio Grande do Sul. A grande habilidade de montar cavalos, a lealdade nas guerras, a confiança no outro, a hospitalidade, a diversão em trabalhos duros e a exibição dos arreios são componentes importantes do jeito de ser do gaúcho. (POA GUIDE, 2016, online).
\end{abstract}

Seguindo a ordem cronológica, é citada a matriz europeia na formação da identidade do gaúcho, a "influência italiana e alemã" no estado, que ocorreu a partir da imigração iniciada em 1824 de famílias dessas duas descendências, tendo como utopia a promessa de que encontrariam ali uma vida próspera. Segundo o aplicativo, esses imigrantes encontraram uma realidade ainda mais dura, mas resistiram e permaneceram, auxiliando na formação cultural do gaúcho contemporâneo: "firme e determinado", que fala e anda de um jeito "forte e impositivo" (POA GUIDE, 2016, online). Outro aspecto enaltecido a respeito do gaúcho é o "orgulho", muitas vezes, entendido como bairrismo. Conforme o aplicativo, o gaúcho se orgulha de sua origem e identidade, o que dá origem a brincadeiras como a de que o estado é "melhor em tudo" ou que as pessoas "[...] primeiro são gaúchas, depois brasileiras [...]" (POA GUIDE, 2016, online). Além disso, também é destacado o papel do futebol na vida do gaúcho, pois o clássico confronto entre Grêmio e Internacional (Gre-Nal) é sempre marcado por forte emoção, com "[...] um show à parte das torcidas $[\ldots] "$, que cantam e gritam durante 90 minutos, tornando o jogo de futebol uma "experiência única" (POA GUIDE, 2016, online).

Os porto alegrenses são narrados como "[...] uma versão atualizada desse gaúcho [...]", devido ao caráter "altamente cosmopolita" da cidade, pois, embora mantenham o jeito "duro" e "sério", são "grandes amigos" quando confiam em alguém, além de serem discretos e diretos no jeito de ser (POA GUIDE, 2016, online). As representações a respeito dos cidadãos porto alegrenses na narrativa do aplicativo, entendidos aqui como personagens de uma história, estão associadas aos seguintes atributos: são "herdeiros" da cultura de um povo "grandioso", que se destaca pela sua "bravura", "lealdade" e "hospitalidade". Ao mesmo tempo, por Porto Alegre é retratada com os atributos de uma grande cidade, e os cidadãos que nela vivem são "amigáveis".

\subsection{Episódios as narrativas sobre os acontecimentos da cidade}

A partir dos Episódios, a análise centrou-se em torno dos eventos narrados no aplicativo. A cidade em movimento, com suas dinâmicas sociais particulares, ganha contornos principalmente com os filtros Festa e Atividade. Com relação às festas, $\mathrm{o}$ aplicativo cita bares famosos da cidade: o IN Sano Pub, a Casa do Lado, o Bar Opinião e o Bar Ocidente. O IN Sano Pub é apresentado como heterogêneo e eclético, local em que se ouve desde salsa e forró até jazz e rock, passando pela MPB, blackmusic e samba rock; a Casa do Lado é narrada como "100\% cabeça aberta", local com público heterogêneo, possuindo os seguintes atributos: "jovem e animado", que é "amigável e viaja bastante" ao ritmo do pop, um local de demonstrações públicas de afeto, "um pouco do que Porto 
Alegre pode oferecer"; o Bar Opinião, que é "o templo do rock", funciona há mais de 30 anos, "fazendo a galera vestir preto e bater a cabeça"; já o Bar Ocidente é o lugar das "festas legendárias", foi criado durante a ditadura militar e nele se reuniam intelectuais para beber, comer e discutir ideias, local que marca a vida da cidade e é "Tão lendário que foi declarado patrimônio cultural da cidade" (POA GUIDE, 2016, online).

Há outras festas na cidade, principalmente nos bairros Centro Histórico e Moinhos de Vento, onde há locais mais populares ou elitizados, respectivamente. Entretanto, o aplicativo apresenta apenas festas localizadas nos bairros Cidade Baixa e Bom Fim, que são conhecidos pelos moradores por serem "alternativos". Percebemos que há um recorte sobre as festas, fazendo com que esses eventos caracterizem a noite porto alegrense como "alternativa", "eclética" e "cabeça aberta", onde diferentes tipos de pessoas são bem-vindas. Além disso, um dos bares é citado como ponto de encontro de intelectuais, reforçando a concepção dos habitantes de que Porto Alegre é uma cidade "progressista" e "culta".

Com relação às atividades, o aplicativo indica locais que proporcionam diferentes experiências para se ter na cidade. Dentre outras, indica o Brique da Redenção, uma feira "gigantesca e movimentadíssima" (POA GUIDE, 2016, online) que funciona aos domingos no Parque Farroupilha, dispondo de performances artísticas e barracas de comida. Também consta o passeio de barco pelo Lago Guaíba, pois, como indaga o aplicativo, "Já que os porto alegrenses adoram olhar pro Lago Guaíba, por que não olhar para Porto Alegre de dentro dele?" (POA GUIDE, 2016, online). Os passeios vão desde a zona sul à zona norte da cidade, em viagens de uma hora, além de possibilitarem vista privilegiada das ilhas próximas. Outro evento narrado é o Acampamento Farroupilha, maior evento de tradicionalismo gaúcho, que ocorre no Parque Harmonia e "relembra a Revolução Farroupilha". Nessa comemoração, centenas de pessoas acampam no parque, revivendo práticas culturais ligadas às tradições do passado, como fazer churrasco, laçar e tratar o gado, usar roupas "típicas", etc.

Também consta na lista de atividades a Arena do Grêmio e o Estádio Beira-Rio, indicação de um estúdio de tatuagens, uma caminhada orientada pelo Centro da cidade, o ônibus de turismo que circula por alguns bairros, as exposições da Fundação Iberê Camargo, a vista do Morro da Pedra Redonda, um passeio coletivo de bicicleta, o Museu de Ciências e Tecnologia e a vista panorâmica da cidade no Morro Santa Tereza.

Assim como no caso das festas, percebemos que as atividades sugeridas pelo aplicativo representam Porto Alegre como uma cidade diversa, com muitas possibilidades de entretenimento. Alguns dos emblemas da cidade são indicados, como o Brique da Redenção, importante lugar de sociabilidade. A narrativa construída a respeito das atividades que dinamizam a cidade evidencia que Porto Alegre possui um escopo de locais que proporcionam experiências desde as mais tradicionais, através da preservação da cultura, como o Acampamento Farroupilha, até as mais vanguardistas, como o Museu de Ciências e Tecnologia.

\subsection{Enredos as narrativas sobre os temas da cidade}

No Enredo, nos atemos a alguns temas destacados pelo aplicativo, questões referentes à tradição e aos costumes das culturas gaúcha e porto alegrense. A alimentação é um dos principais aspectos que caracterizam qualquer cultura, pois o alimento está imbuído de significados e, conforme Lucena (2008), a alimentação possui função identitária e socialmente construída. É através dos rituais de consumo dos alimentos que estabelecemos parte de nossas relações de afeto, tanto com o ambiente como com os outros integrantes de nossa cultura.

\begin{abstract}
Sob a perspectiva das práticas culturais podem-se enfatizar modos de cozinhar, técnicas, utensílios utilizados na preparação dos alimentos, tradições, papéis masculinos e femininos e ainda textos de receitas registrados na oralidade e na memória. [...] A maneira de cozinhar e os hábitos de servir a mesa são indicadores de uma adesão aos valores e comportamentos locais. (LUCENA, 2008, p. 178).
\end{abstract}

A respeito da alimentação, recebem destaque no aplicativo o churrasco e o chimarrão, alocados na guia Curiosidades. O "tradicional churrasco de domingo", como se refere o 
aplicativo, é feito com cortes de carnes que possuem nomes específicos no estado, pois os pedaços de carne "[...] são fincados em espetos e sobrepostos sobre brasas de carvão [...]", para então assar (POA GUIDE, 2016, online). A respeito dessa iguaria, o aplicativo ressalta que são os homens que preparam o churrasco, tradição que passa de pai para filho.

O chimarrão, um dos símbolos da cultura gaúcha, é apresentado como sendo a "primeira atividade do dia de vários gaúchos" (POA GUIDE, 2016, online), além de sugerir algumas dicas de consumo: "não mexer na bomba", pois além de desrespeitoso, estraga a posição da erva-mate; e tomar o chimarrão até escutar o "ronco", para então repor a água e passar para o próximo. A importância da bebida é ressaltada pela citação de que, em alguns parques ou dentro de empresas, encontramos máquinas com água quente. $\mathrm{O}$ caráter de sociabilidade é mais uma vez lembrado pelo aplicativo: "Compartilhar a mesma roda de chimarrão é uma forma de demonstrar confiança e união" (POA GUIDE, 2016, online). Além desses aspectos, o aplicativo ainda informa a origem da bebida:

\begin{abstract}
Chimarrão é uma bebida indígena, herança das tribos que costumavam viver nessa região. Dizem que o primeiro homem branco a prová-lo foi o general espanhol Domingo Martinez, em 1554. Ele teria começado, assim, a espalhar o hábito de tomar chimarrão em acampamentos na região dos pampas. (POA GUIDE, 2016, online).
\end{abstract}

Outro tema importante que caracteriza uma cultura é a linguagem, pois a comunicação é fator crucial na sociabilidade, na manutenção das tradições, na troca de afetos e, consequentemente, na formação da memória social. O Porto Alegre Guide possui uma área específica a esse respeito, denominada Doses de Gauchês, onde apresenta um mini-dicionário com 22 gírias que marcam o linguajar do gaúcho.

\subsection{Cenários: as narrativas sobre os lugares da cidade}

Nos Cenários, apresentamos a narrativa que o aplicativo constrói a respeito dos espaços da cidade e de suas características e peculiaridades. Conforme Maffesoli (1994), a cidade é uma "nebulosa noética", lugar do fluxo afetivo, das manifestações estéticas, dos movimentos éticos, possuindo um aspecto não-racional, o que relembra sua dimensão "fluida". Para o autor, esta "coisa" física só pode existir por meio do discurso multiforme que a diz ou vê. $\mathrm{O}$ autor destaca a questão da apropriação imaginária da cidade pelo cidadão:

Que seja através dos grandes
'espaços de celebração' emblemáticos
ou dos pequenos 'espaços de
celebração' cotidianos, atravessamos,
intencionalmente ou não, uma série de
paisagens, uma série de situações, que
desenham uma geografia imaginária,
que permite se acomodar (no sentido
ótico) ao ambiente físico que é dado,
e que ao mesmo tempo eu construo
simbolicamente. (MAFFESOLI, I994, p.
66 ).

Os espaços da cidade, nesse sentido, se constituem da forma como os imaginamos ou como são narrados. Identificamos algumas características de Porto Alegre destacadas no espaço Curiosidades do aplicativo. Um aspecto ressaltado é que Porto Alegre é uma "cidade verde", pois seu desenvolvimento econômico não se sobrepôs aos valores "antigos" dos gaúchos, como o "respeito à natureza". Uma das cidades mais arborizadas do país, conta com aproximadamente 1,5 milhão de árvores, quase 600 praças e oito grandes parques arborizados (POA GUIDE, 2016, online). Outra característica citada é que Porto Alegre é "fanática por futebol", tanto que alguns torcedores chegam a tatuar o símbolo de seus times no corpo, pois "discutir sobre Grêmio e Internacional é um esporte por si só para os gaúchos" (POA GUIDE, 2016, online).

Buscando contrariar a concepção de que Porto Alegre é uma cidade conservadora e machista, devido à cultura gaúcha, o espaço Alternativa e Mente Aberta do aplicativo ressalta que na cidade "[...] há coexistência entre todo o tipo de diversidade no dia a dia [...]" (POA GUIDE, 2016), sendo uma das cidades mais tolerantes do Brasil com diferentes estilos de vida, classes econômicas e opções sexuais. Percebemos aqui que o aplicativo tenta desconstruir um preconceito em relação à cidade, evidenciando que, apesar de seu tradicionalismo, Porto Alegre é uma cidade sensível às liberdades, 
configurando-se como "vanguardista" e "progressista".

Além disso, outra curiosidade apontada é que a cidade possui o pôr-do-sol mais bonito do mundo, "[...] pois o céu fica pintado de rosa e roxo enquanto é refletido no lago Guaíba (popularmente chamado de 'rio' Guaíba, de forma errônea) [...]" (POA GUIDE, 2016, online). Ainda é citado que assistir ao pôr-do-sol é uma atividade muito praticada pelos moradores e visitantes, sendo os melhores locais para isso são o Cais do Porto, o Gasômetro e a Praia de Ipanema, na zona sul. Embora possivelmente questionável, a afirmação de que o pôr-do-sol da cidade é o mais bonito encontra respaldo nas representações que os cidadãos constroem sobre ela, fruto de suas experiências e, portanto, é uma visão permeada de afetos e de subjetividade.

Os cenários da cidade são expressos através das imagens, dentre outros recursos utilizados pelo aplicativo, na navegação pelos pontos turísticos de Porto Alegre, em que a narrativa possibilita aos usuários transitarem nos diversos espaços, praças, monumentos, avenidas, entre outros, tornando visível a cidade virtual. Utilizando o filtro Ponto Turístico, identificamos lugares da cidade considerados de interesse do turista que a visita. O que chama atenção é que essa seleção indica 31 lugares localizados nos bairros Centro Histórico (17), Cidade Baixa (4), Moinhos de Vento (4), Bom Fim (2) e em outros bairros (4). Ou seja, dos 81 bairros que compõe a cidade, apenas quatro, que são centrais ou nobres, recebem destaque no aplicativo e têm seus lugares mencionados como pontos turísticos.

Para ilustrar, assinalamos no Mapa 1 a localização dos lugares citados. A intervenção foi feita sobre o mapa dos bairros oficiais de Porto Alegre $^{1}$ e assinalamos apenas os pontos indicados no bairro Centro Histórico, pois a visibilidade do mapa ficaria comprometida se apresentássemos os outros bairros, onde há poucos pontos turísticos. No total, foram citados 17 lugares do bairro, mas no mapa assinalamos apenas 16 , pois a Super Cuia, indicada pelo aplicativo, na verdade está localizada no bairro Praia de Belas, ao sul do Centro Histórico.

I PREFEITURA MUNICIPAL DE PORTO ALEGRE. Secretaria do Planejamento Municipal. Bairros Vigentes. Porto Alegre: GESPM, 201 I. Disponível em: <lproweb.procempa.com.br/pmpa/prefpoa/spm/ usu_doc/bairros_vigentes_ultima_versao_20II.pdf $>$. Acesso em: 5 jul. 2016.
Mapa 1 - Pontos Turísticos no Centro Histórico no Porto Alegre Guide

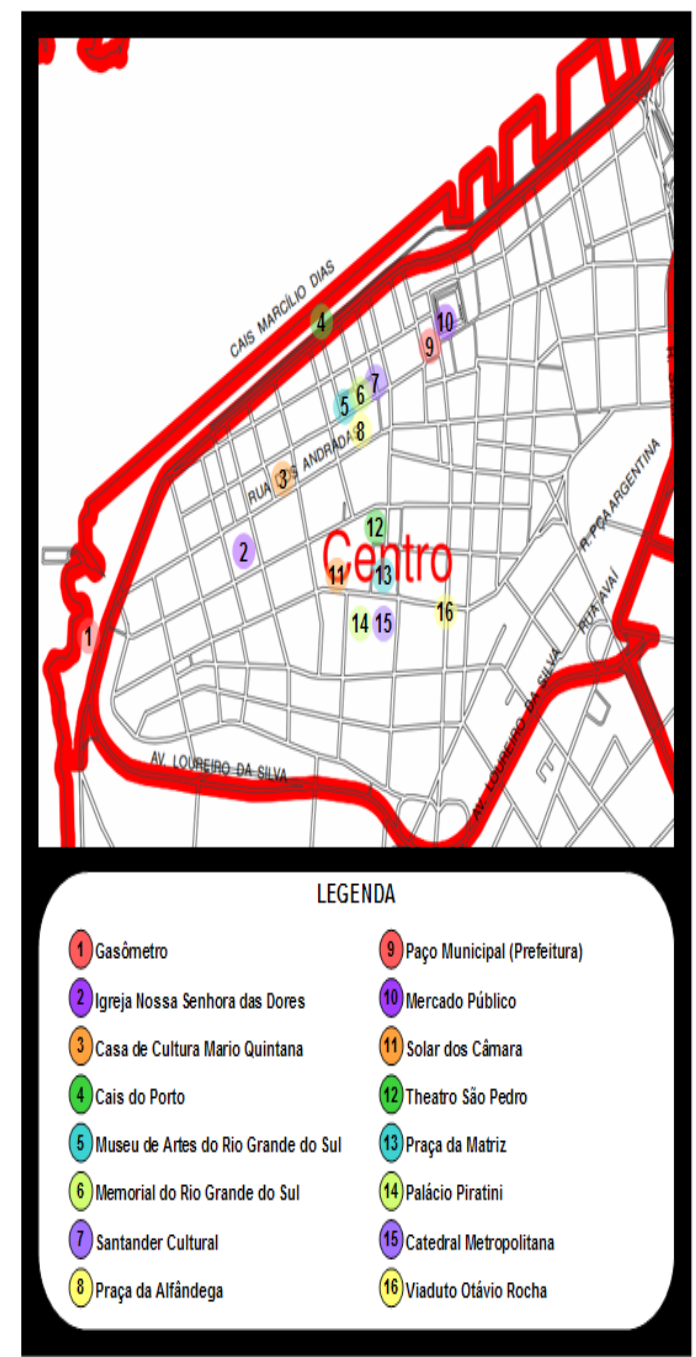

Fonte: os autores (2016)

A narrativa sobre a cidade e seus espaços sugere aos usuários um trajeto no qual estes também deixam rastros informacionais pela sua passagem. Segundo Bruno (2012, p. 687), o rastro digital é "[...] um vestígio de uma ação efetuada por um indivíduo qualquer no ciberespaço [...]" e "[...] acompanha necessariamente toda ação, salvo que medidas para evitá-lo sejam tomadas". Além disso, nesse transitar entre os espaços, podem ser visitados - virtual e presencialmente ambientes patrimonializados.

De acordo com o site do Instituto do Patrimônio Histórico e Artístico do Estado do Rio Grande do Sul (2015), são 26 os bens 
tombados em Porto Alegre pelo estado. Destes, identificamos sete inseridos no aplicativo: Agência Matriz do Banco Meridional (atual Santander Cultural), Palácio Piratini, Capela Positivista de Porto Alegre, Hotel Majestic (atual Casa de Cultura Mario Quintana), Praça da Alfândega, Theatro São Pedro e Usina do Gasômetro. Se utilizarmos o raciocínio de Nora, de que "[...] a memória é um fenômeno sempre atual, um elo vivido no eterno presente; a história, uma representação do passado" (NORA, 1993, p. 54), temos no aplicativo a presença desses dois elementos.

A memória social perpassa a narrativa da cidade, principalmente se considerarmos que Porto Alegre Guide é um aplicativo interativo que permite o envio de informações através de sugestões de conteúdo. Assim, a narrativa possibilita aos moradores e visitantes o compartilhamento das informações sobre seus lugares preferidos, deixando fluir a memória afetiva através das suas lembranças em relação aos espaços da cidade.

Além disso, os lugares carregam uma materialidade, que é parte significativa da vida das pessoas, pois "[...] nosso ambiente material traz ao mesmo tempo a nossa marca e a dos outros" (HALBWACHS, 2006, p. 157). E o que seria o turista, descobrindo Porto Alegre, senão alguém que deixa e carrega marcas ao percorrer estes espaços? Podemos sugerir que ele, ao percorrer a cidade através do aplicativo, se insere, não só na história, mas na criação de uma memória do local, de seus habitantes e dele próprio.

Para Assmann (2011), mesmo quando não há uma memória imanente nos locais, eles são parte significante na criação de espaços culturais de recordação, pois, além de solidificarem e validarem a recordação, a ancorando no chão, corporificam uma continuidade da duração. Dessa maneira, a relativamente breve recordação de indivíduos, culturas e épocas, materializada nos artefatos é superada por estes locais.

Podemos pensar, por exemplo, na Ponte de Pedra e em sua corporeidade como local de recordação. De local de passagem, representando a única passagem entre $\mathrm{o}$ bairro Menino Deus e o Centro Histórico de Porto Alegre, foi ressignificada como monumento urbano, integrando a paisagem histórica e turística da cidade (VIVA O CENTRO, 2016). Mesmo assim, mantém sua ligação com o passado, inclusive no nome do local em que está construída: Largo dos Açorianos. Podemos pensar então que o aplicativo aproxima, por meio do mapa, o turista desses locais e, consequentemente, faz com que a narrativa agregue à essa experiência as lembranças do viajante.

\subsection{Sequências cronológicas 0 tempo nas narrativas da cidade}

O componente humano está presente na cronologia da cidade através da citação daqueles que fazem parte de sua memória, criando uma narrativa entrelaçada nos fatos históricos da capital gaúcha. Como exemplo, temos os seguintes porto alegrenses famosos: o artista Iberê Camargo e o poeta Mario Quintana. Os dois nominam importantes locais de Porto Alegre: uma fundação, de cunho museal; e um centro cultural, respectivamente.

Assim, chegamos às Sequências cronológicas, categoria que diz respeito à temporalidade narrada e à evolução da cidade ao longo do tempo. Temos, então, um passado mais longínquo, que envolve o legado de dois artistas em seus campos, um dos pincéis e outro das palavras; um passado mais recente, caracterizado pela criação dos espaços culturais, marcando uma nova narrativa; bem como o presente e o futuro, com a ocupação dos espaços por outros agentes e manifestações culturais. Nesta ótica, o aplicativo exerce uma função inteligente, pois possibilita que as pessoas realizem interconexões ao acionarem a narrativa do aplicativo, integrando temporal, contextual e espacialmente essas diferentes narrativas sobre a cidade.

A temporalidade na narrativa do aplicativo sobre Porto Alegre nos permite afirmar que a cidade mescla elementos de passado, presente e futuro. Ela é narrada a partir de fragmentos dispersos da história, do passado e do presente que se misturam como uma bricolagem. Também possui características que lembram as pequenas cidades e ao mesmo tempo é cosmopolita, pois nela convivem elementos culturais ligados às tradições e também adeptos do modo de vida contemporâneo. Um exemplo disso é a realização do Acampamento Farroupilha no Parque Harmonia e a realização de festas alternativas nos bairros Cidade Baixa e Bom Fim.

Assim, o porto alegrense, embora imerso em uma cidade com aspectos cosmopolitas, 
conserva e resguarda elementos do passado através da preservação de prédios que fazem parte do patrimônio histórico da cidade, além das suas crenças, linguagens e costumes da cultura local. As mesmas mãos que seguram o espeto do churrasco e a cuia do chimarrão também seguram o aparelho celular que o cidadão porto alegrense usa para acessar o Porto Alegre Guidee sugerir informações sobre a sua cidade.

Também podemos ressaltar a presença de diferentes temporalidades na conexão entre o usuário do aplicativo e o próprio percurso na criação de uma nova narrativa. Enquanto o usuário transita pela cidade, entra em contato com as experiências de seu próprio passado, no presente. De acordo com Sarlo (2007), a lembrança é insistente por ser, de certo modo, soberana e incontrolável; o passado se faz presente. Assim, mesmo que seja a primeira vez que o visitante está entrando em contato com Porto Alegre, ele mantém um elo com o seu próprio passado, ele presentifica seu passado.

Seja pelos aromas, sabores, experiências, pessoas ou semelhanças arquitetônicas, o gatilho da lembrança é acionado, podendo o aproximar ou o afastar afetivamente daquele local. É como aquela rua que vimos em uma viagem e se assemelha a uma rua de nossa própria cidade; ou aquele prato típico que nos transporta para a mesa do almoço de domingo na casa da avó; algo acontece e uma conexão com nossas lembranças nos rebate. Do mesmo modo, o esquecimento se faz presente, articulando seu embate com a lembrança.

Assim, abordar o esquecimento é importante quando falamos da relação entre cidade, narração e temporalidade. Se pensarmos em uma cronologia embasada na memória oficial, refletida nos espaços da cidade, a narrativa originada pela memória dos habitantespode divergir desta, trazendo uma outra aproximação entre o turista e o local. Dessa maneira, se a proposta do aplicativo é ser feito por moradores locais, a memória dos habitantes pode se sobressair à memória oficial e/ou locais importantes para a história de Porto Alegre, desconhecidos do grande público, podem não ser contemplados.

Outra abordagem sugerida pelo aplicativo Porto Alegre Guide é a de que o guia é uma excelente oportunidade para "porto alegrenses experimentarem a cidade com um olhar de visitante" (POA GUIDE, 2016, online). Com esta afirmação, podemos supor que, ao mesmo tempo em que o habitante tem uma nova experiência em sua relação com a cidade, ele entra em contato com duas narrativas, a oficial e a narrada por outros moradores. Além disso, o morador tem uma terceira conexão com a cidade que excede esses dois aspectos: a memória afetiva. Esse aspecto irá se pronunciar ainda mais se existir algum tipo de conexão com os locais de maior destaque dentro do aplicativo.

Como exemplo, podemos citar a Usina do Gasômetro e sua área de lazer, frequentada por um grande número de porto alegrenses, seus amigos e familiares aos domingos. Mais do que um espaço para a prática de esportes, este local se torna ambiente para a socialização, um pontode-encontro da cidade, tendo como pano de fundo um dos cartões-postais mais presentes na memória afetiva dos habitantes de Porto Alegre: o pôr-do-sol no Guaíba.

\section{CONSIDERAÇÕES FINAIS}

Nosso intuito nesse estudo não foi abranger todas as informações disponíveis no Porto Alegre Guide, mas analisar de que modo as informações divulgadas por ele auxiliam na construção das representações sobre Porto Alegre. A narrativa do aplicativo proporciona aos cidadãos, aos visitantes e ao mundo, informações físicas sobre a cidade, se constituindo uma fonte de informação local e global potencializada pela comunicação interativa. A cidade, para além de uma demarcação territorial e física, é também um lugar de memória, constituído por lembranças e esquecimentos, com um trajeto que, ao ser criado coletivamente pelos moradores no aplicativo, induz o turista a percorrer outros espaços de Porto Alegre. Nesta viagem, os cidadãos podem entrar em contato com memórias inusitadas ou enquadradas.

Obviamente, seria ingênuo pensarmos em uma totalidade da memória, mas é possível perceber um direcionamento que invisibiliza territórios, bem como agentes sociais e culturais. O aplicativo ressalta a diversidade que caracteriza a cidade contemporânea, mas não informa, por exemplo, a importância dos negros na história de Porto Alegre, que junto com os descendentes de italianos e alemães, atuaram 
no desenvolvimento da cidade. Como exemplo, o aplicativo poderia indicar a visita ao Museu de Percurso do Negro, projeto que busca "[...] visibilizar a comunidade afrobrasileira com a instalação de obras de arte em espaços públicos da cidade" (MUSEU DE..., 2016, online), mas em nenhum momento esse museu é mencionado.

$\mathrm{O}$ estudo evidenciou que o aplicativo é composto por informações sobre lugares predominantemente localizados no Centro, BomFim, MoinhosdeVento e CidadeBaixa, bairros centrais da cidade, com raras exceções que fogem desta rota. Desse modo, o aplicativo constrói uma narrativa que legitima os espaços centrais da cidade em detrimento da periferia. Ao proceder com esse recorte, os holofotes se voltam para os bairros históricos ou nobres, gerando invisibilidade às outras áreas.

A narratologia forneceu os elementos que nos orientaram para realizar uma análise transversal dos conteúdos informativos divulgados pelo aplicativo. $\mathrm{O}$ enredo, as personagens, os cenários, os episódios e as sequências cronológicas perpassam as informações sobre o cotidiano da cidade, entendidas como narrativas. Assim, foi possível analisarmos as características dos cidadãos que vivem na cidade, os lugares que nela encontramos, os acontecimentos que a dinamizam, os assuntos que perpassam a fala e as tradições da cultura local. Tais elementos não destoam uns dos outros, pois percebemos que todos convergem para uma mesma narrativa que reforça a ideia de que, ao mesmo tempo em que Porto Alegre carrega consigo traços de tradicionalismo, também é uma cidade aberta às transformações contemporâneas.

A narrativa do aplicativo sobre Porto Alegre ultrapassa a dimensão física, pois engloba elementos simbólicos que envolvem os imaginários e as interações dos cidadãos com a cidade e seus espaços. Ela é marcada por informações que dizem respeito a conteúdos que tratam da identidade cultural, dos intercâmbios, dos lugares de encontro e das lembranças. Deste modo, o aplicativo e a sua narrativa atuam no compartilhamento das informações sobre a cidade e nos interesses comuns dos cidadãos e das comunidades regionais e globais. Pelo seu caráter colaborativo, o aplicativo está aberto a edições constantes, o que altera o seu fluxo informacional, influenciando na narrativa construída por ele.

Nas narrativas do Porto Alegre Guide, a cidade é narrada como um lugar que agrega os valores e tradições do passado ao vanguardismo e às novas demandas do presente, sempre aberta ao futuro. Essa narrativa apresenta a cidade como um lugar com uma rica história, orgulhosa de seus feitos e de seus cidadãos, mas também disposta a receber bem quem vem de fora, tornando-a alternativa e eclética. E é nessa zona de transição entre passado e futuro, tradição e vanguardismo, enaltecida pelos fluxos informacionais, que se formam as memórias dessa cidade.

Artigo recebido em 3 I/I0/2016 e aceito para publicação em I8/0I/20I7

\section{NARRATIVES OF THE CITY IN THE APP PORTO ALEGRE GUIDE}

ABSTRACT

The article analyzes the information available in a mobile app about the city and its relationship with the social memory. Includes the information flows that structure the app and work in the virtualization of the city. To navigate the city through its virtual representation, informational traces of our passage are generated, which contributes to build narratives about it. Uses narratology as a method for analyzing the information available in the app Porto Alegre Guide, characterizing it as a source of information about the city and its memory. Focuses on the analysis of information that treat the plots, episodes, characters, scenarios and chronological sequences that composes the stories narrated by the app. Concludes that all these elements, although different, converge to the same narrative: Porto Alegre is a city that combines the traditions of the past and the vanguard of this, while it remains open to future changes.

Keywords: $\quad$ Porto Alegre Guide. Narrative. Social Memory. Mobile App. 


\section{REFERÊNCIAS}

ASSMANN, A. Espaços da recordação: formas e transformações da memória cultural. São Paulo: Editora da Unicamp, 2011.

BARBOSA, M. F. Experiência e narrativa. Salvador: Edufba, 2003.

BONI, P. C.; HOFFMANN, M. L. Guardião de imagens: "memórias fotográficas" e a relação de pertencimento de um pioneiro em Londrina. Em Questão, Porto Alegre, v. 17, n. 2, p. 147-164, jul./dez. 2011.

BRUNO, F. Rastros digitais sob a perspectiva da teoria ator-rede. Revista FAMECOS, Porto Alegre, v. 19, n. 3, p. 681-704, 2012.

CALVINO, Italo. As cidades invisíveis. Editora Companhia das Letras, 1990.

CAPURRO, R. Epistemologia e Ciência da informação. In: ENCONTRO NACIONAL DE PESQUISA EM CIÊNCIA DA INFORMAÇÃO, 5., 2003, Belo Horizonte. Anais... Belo Horizonte: ECI/UFMG, 2003.

DODEBEI, V. Memoração e patrimonialização em três tempos: mito, razão e interação digital. TARDY, C.; DODEBEI, V. (Org.). Memória e novos patrimônios. Marseille: OpenEdition Press, 2015.

GONDAR, J. Cinco proposições sobre memória social. DODEBEI, V.; FARIAS, F. R.; GONDAR, J. (Org.). Revista Morpheus, Rio de Janeiro, v. 9, n. 15, 2016.

HALBWACHS, M. A memória coletiva. 2. ed. São Paulo: Centauro Editora, 2006.

INSTITUTO DO PATRIMÔNIO HISTÓRICO E ARTÍSTICO DO ESTADO. Disponível em: $\quad<$ http://www.iphae.rs.gov.br/Main. php?do=BensTombadosAc\&Clr=1>. Acesso em: 5 jul. 2016.

JEDLOWSKI, P. Memoryandsociology: themesandissues. Time \&Society, v. 10, n. 1, p. 29-44, 2001.
LATOUR, B. Redes que a razão desconhece: laboratórios, bibliotecas, coleções. In: PARENTE, A. (Org.). Tramas da rede: novas dimensões filosóficas, estéticas e política da comunicação. Porto Alegre: Sulina, 2004. p. 39-63.

LEITE, L. C. M. O foco narrativo. 8. ed. São Paulo: Ática, 1997.

LUCENA, C. T. Comida em festa: cozinheiros, doceiras e festeiros. In: LUCENA, C. T.; CAMPOS, M. C. S. S. (Org.). Práticas e representações. São Paulo: Humanitas/CERU, 2008

MAFFESOLI, M. O poder dos espaços de celebração. Revista TB, Rio de Janeiro, n. 116, p. 59-70, jan./mar. 1994.

MARONNA, M.; VILELA, R. S. Conhecer para intervir: infância, violência e mídia: propósitos, projeto de investigação e conclusões comuns. In: MORIGI, V. J.; ROSA, R.; MEURER, F. (Org.). Mídia e representações da infância: narrativas contemporâneas. Curitiba: Champagnat; Porto Alegre: UFRGS, 2007. p. 19-56.

MARTELETO, R. M. Cultura, educação, distribuição social dos bens simbólicos e excedente informacional. Informare, Rio de Janeiro, v. 1, n. 2, p. 11-23, 1995.

MOTTA, L. G. Análise crítica da narrativa. Brasília: Editora UnB, 2013.

MUSEU DE PERCURSO DO NEGRO EM PORTO ALEGRE. Disponível em: <http:// museudepercursodonegroem portoalegre. blogspot.com.br/>. Acesso em: 11 jul. 2016.

NORA, P. Entre memória e história: a problemática dos lugares. Projeto História, São Paulo, v. 10, 1993.

POA GUIDE - Apps para Android no Google Play. Disponível em: <https://play.google. com/store/apps/details?id=br.com.fivecoders. poaguide\&hl=pt_BR>. Acessoem: 5 jul. 2016.

SÁ, C. P de. Sobre o campo de estudo da memória social: uma perspectiva psicossocial. 
Psicologia: Reflexão e Crítica, Porto Alegre, v. 20, VAN DIJCK, J. Mediated memories in the n. 2, p. 290-295, 2007. digital age. Stanford University Press, 2007.

SARLO, B. Tempo passado: cultura da memória e guinada subjetiva. Companhia das letras, 2007.

VIVA O CENTRO. Disponível em: <http:// lproweb.procempa.com.br/pmpa/prefpoa/ vivaocentro/default.php?p_secao=67>. Acesso em: 23 out. 2016. 